POLSKA AKADEMIA UMIEJĘTNOŚCI

Agata KRZYwdZińSKA

Uniwersytet Jagielloński w Krakowie

\title{
WARTOŚCI W POLSKICH I ROSYJSKICH MEDIACH
}

\author{
VALUES IN POLISH AND RUSSIAN MEDIA
}

\begin{abstract}
Streszczenie
Temat wartości można rozpatrywać na rozmaitych poziomach - komunikowania wartości w misji mediów, wartości w formach i treściach medialnych, wartościach zawodu dziennikarza i dziennikarstwa. Ten artykuł skupia się na wartościach zawodu dziennikarza, jest analizą problematyki prawno-etyczno-deontologicznej zawodu oraz kultury dziennikarskiej w Polsce i Rosji.
\end{abstract}

\section{Summary}

The journalistic ethics matter can be considered on many levels - values communicated in the media, principles in media content and values of journalism and journalism. The article is an analysis of legal, ethical and deontological issues related to journalistic profession and journalism culture in Poland and Russia.

Słowa kluczowe: kultura dziennikarska w Polsce i w Rosji, zasady dziennikarskie, etyczne, wartości, normy, polsko-rosyjskie relacje

Keywords: journalistic culture in Poland, Russia, journalism ethics and principles, values, norms, Polish-Russian relations

Rosyjska i polska kultura medialna są włączone w określoną sferę wartości. Stan współczesnych polskich i rosyjskich mediów to nie tylko przekazywane przez nie wartości, lecz także jakość i wartość samych mediów. Wartość raz może być celem, innym razem kryterium wyboru celów, może być utożsamiana z normą społeczną. Hierarchia wartości, które tworzą kulturę w danym społeczeństwie, uzależniona jest 
od systemu sprawowania władzy, od warunków społeczno-ekonomicznych i tradycji narodowych. Literatura przedmiotowa pokazuje, że typologie i hierarchie wartości są niejednorodne, niemniej jedną z najbardziej rozpoznawalnych jest typologia Maxa Schellera, który przyjął podział na wartości społeczno-kulturowe (cenione lub negowane), wartości duchowe (poznawcze typu prawda lub brak wiedzy), hedonistyczne (pozytywne i negatywne), witalne (np. życia i śmierci), estetyczne (typu piękno-brzydota), moralne i transcendentne (typu dobro i zło) ${ }^{1}$. Hierarchia wartości w mediach jest ważna, nie mniej istotne wydają się funkcje, które pełnią wartości (typologia za Leszkiem Jazownikiem), przez co rozumiemy funkcje motywujące, integrujące, normalizujące, tożsamotwórcze ${ }^{2}$. Typologia i funkcje wartości są istotne dla podkreślenia, jakie zasady etyczno-prawno-deontologiczne tkwią u podstaw zawodu dziennikarskiego w Polsce i Rosji.

\section{Problematyka prawno-etyczno-deontologiczna zawodu}

W świetle obowiązującej w Polsce ustawy z 26 stycznia 1984 r. - Prawo prasowe w myśl art. 10 ust. 1 ,zadaniem dziennikarza jest służba społeczeństwu i państwu”3. Dziennikarz ma obowiązek działania zgodnie z etyką zawodową i zasadami współżycia społecznego, w granicach określonych przepisami prawa. Co oznaczają zasady współżycia społecznego? Oznaczają odwoływanie się do powszechnie uznawanych w kulturze naszego społeczeństwa wartości, które są zarazem dziedzictwem i składnikiem kultury europejskiej. Ustawodawca określił równocześnie, że w przypadku pracy zawodowej dziennikarza pojawi się konflikt na linii służby społeczeństwu i państwu a realizacji linii programowej; obowiązkiem dziennikarza jest wybór tych wartości, które ustawodawca wymienia w ustawie ${ }^{4}$.

Nie sposób nie mówić o wartościach, nie odwołując się do obowiązujących kodeksów etycznych, które są źródłem aksjologii dziennikarskiej. W dniu 29 marca 1995 r. Kartę Etyczną Mediów podpisali prezesi: Stowarzyszenia Dziennikarzy Polskich, Stowarzyszenia Dziennikarzy Rzeczypospolitej Polskiej, Katolickiego Stowarzyszenia Dziennikarzy, Syndykatu Dziennikarzy Polskich, Związku Zawodowego Dziennikarzy, Unii Wydawców Prasy, Telewizji Polskiej S.A., Telewizji Polsat, Stowarzyszenia Niezależnych Producentów Filmowych i Telewizyjnych, Polskiego Radia S.A., Stowarzyszenia Radia Publicznego w Polsce, Stowarzyszenia Polskiej Prywatnej

${ }^{1}$ J. Puzynina, Wartości, etyka, sacrum w języku [w:] Polonistyka w przebudowie, t. 2, red. M. Czermińska i in., Kraków 2005, s. 340.

${ }^{2}$ L. Jazownik, Społeczny sens oraz społeczne funkcjonowanie wartości, aksjologii i edukacji aksjologicznej. Analiza metadyskursywna i jej edukacyjne implikacje [w:] Czytanie tekstów kultury. Metodologia - badania - metodyka, red. B. Myrdzik, I. Morawska, Lublin 2007.

${ }^{3}$ Dz. U. nr 5, poz. 24 ze zm.

${ }^{4}$ Ibidem. 
Radiofonii, Związku Zawodowego Dziennikarzy Radia i Telewizji, Związku Zawodowego Pracowników Twórczych TVP SA WIZJA oraz krajowy duszpasterz środowisk twórczych, ks. Wiesław Niewęgłowski. Karta zawiera siedem zasad: prawdy, obiektywizmu, oddzielania informacji od komentarza, uczciwości, szacunku i tolerancji, pierwszeństwa dobra odbiorcy, wolności i odpowiedzialności.

Zasady etyczne omawia także Dziennikarski Kodeks Obyczajowy SDP; szczegółowo uwrażliwia dziennikarzy, by kierowali się dobrem czytelników, widzów i słuchaczy i nigdy nie posługiwali się metodami sprzecznymi z prawem i nagannymi etycznie; ponadto dziennikarz powinien okazywać szacunek odbiorcom o odmiennych poglądach ideowych, kulturowych czy obyczajowych, nawet jeśli sam ma inny światopogląd.

W Dziennikarskim Kodeksie Obyczajowym zapisano:

Obowiązkiem dziennikarza jest poszanowanie wartości uniwersalnych, kultury i tradycji narodowej, postaw i przekonań religijnych oraz poglądów osób niewierzących, tolerancja dla odrębności kulturowych i obyczajowych ${ }^{5}$.

Dziennikarz świadomie wybiera i akceptuje politykę redakcyjną gazety, pisma czy stacji, w której pracuje, niemniej zachowuje prawo do własnych poglądów oraz do odmowy wykonania zadań dziennikarskich niezgodnych z jego przekonaniami, normami etycznymi bądź prawnymi 6 .

Natomiast Kodeks Obyczajowy przyjęty przez Stowarzyszenie Dziennikarzy Rzeczypospolitej Polskiej (SDRP) to 15 zasad etycznych, które obowiązują dziennikarzy, członków stowarzyszenia. Kodeks w pierwszym punkcie podkreśla, że podstawowym obowiązkiem etycznym dziennikarza jest poszukiwanie i publikowanie prawdy i tę wartość uznaje za naczelną dla dziennikarstwa?

Wszelkie spory dotyczące spraw wątpliwych etycznie może w Polsce rozpatrywać Rada Etyki Mediów, jednak jest ona tylko organem opiniodawczym, nie może wydawać żadnych sankcji. Problemów etycznych każdego roku przybywa, a opinie na ten temat są udostępniane publicznie przez Radę na jej stronie internetowej. Z kolei na członków SDP można nałożyć karę, upomnienie, usunać ze stowarzyszenia, a Naczelny Sąd Dziennikarski może orzec ogłoszenie werdyktu w mediach ${ }^{8}$.

Zasady, którymi powinien kierować się rosyjski dziennikarz, są sformułowane w ustawie o środkach masowej informacji z 27 grudnia $1991 \mathrm{r}$. Ustawodawca definiuje prawa i obowiązki dziennikarzy w art. $47 \mathrm{w}$ rozdziale „Права и обязанности журналиста". W artykule tym rosyjski ustawodawca informuje, że dziennikarz ma

${ }^{5}$ Dziennikarski Kodeks Obyczajowy, http://www.krrit.gov.pl/Data/Files/_public/pliki/publikacje/ analiza2006_07.pdf (dostęp: 12.09.2016).

${ }^{6}$ Ibidem.

${ }^{7} \mathrm{http}: / /$ centruminformacji.tvp.pl/15781040/dziennikarski-kodeks-obyczajowy-stowarzyszeniadziennikarzy-rzeczypospolitej-polskiej (dostęp: 15.09.2016).

${ }^{8}$ www.sdp.pl/kodeks (dostęp: 15.09.2016). 
prawo zbierać informacje, publikować swoje sądy i oceny w artykułach, jak również odmówić przygotowywania tekstów, które są sprzeczne z jego poglądami. $Z$ drugiej strony jednak w art. 29 ustawy czytamy, że dziennikarz jest zobowiązany do wypełniania obowiązków narzuconych mu w ramach stosunku pracy. Państwo ze swojej strony gwarantuje ochronę zdrowia, życia, dobrego imienia i godności dziennikarza (pkt 10). W artykułach nie ma w ogóle informacji o tym, że dziennikarz powinien działać zgodnie z etyką zawodową.

O etycznym postępowaniu dziennikarzy informuje natomiast Kodeks Etyki Dziennikarskiej, który został przyjęty na Kongresie Dziennikarzy Związku Dziennikarzy Rosji 24 czerwca 1994 r. Kodeks zobowiązuje członków-dziennikarzy największej organizacji dziennikarskiej w Rosji do przestrzegania zasad etyki zawodowej, uwzględniając również aspekt moralny. Rosyjski dziennikarz jest zobowiązany do powstrzymywania się od komentarzy czy aluzji dotyczących rasy, narodowości, koloru skóry, religii, pochodzenia społecznego; jest zobowiązany do ochrony interesów obywateli rosyjskich; powinien szanować swoje źródła informacji i swoich kolegów. Jedynie gdy mowa o ewentualnym uszczerbku spowodowanym przez dziennikarza w stosunku do swoich kolegów, pada akcent na przymiotnik „moralny”. Słowo „wartość” nie pada jednak w kodeksie ani razu, natomiast używany jest wyraz „zasady”. Kodeks kończy się ogólnikową informacją o tym, że dziennikarz może odstąpić od wypełniania swoich obowiązków, jeśli naruszą one zasady wymienione w kodeksie. Redaktorzy, w tym członkowie największej instytucji zrzeszającej dziennikarzy w Rosji Związku Dziennikarzy Rosji - uważają, że kodeks się częściowo zdezaktualizował, dlatego przygotowano nowy projekt, który jest dyskutowany w środowisku dziennikarskim ${ }^{9}$. Instytucją nadzorującą media i udzielającą ostrzeżeń rosyjskim dziennikarzom i redakcjom jest Rosyjska Federalna Służba Nadzoru (Roskomnadzor) ${ }^{10}$. Zgodnie $\mathrm{z}$ rosyjskim prawem dwa upomnienia w ciagu roku ze strony Roskomnadzoru mogą skutkować zamknięciem tytułu prasowego, który je otrzymał.

\section{Przemiany dziennikarstwa w Polsce i w Rosji}

W październiku 2013 r. ukazał się wstępny raport zatytułowany „Przemiany dziennikarstwa w Polsce, Rosji i Szwecji”. Jest to jednocześnie tytuł projektu naukowego, realizowanego przez medioznawców z Sodertorn University w Sztokholmie przy współpracy z naukowcami z Polski (z Uniwersytetu Wrocławskiego) i Rosji (z Uniwersytetu im. Łomonosowa w Moskwie). Projekt obejmuje lata 20112014, jednak jego założenia i pierwsze wyniki zostały już zaprezentowane w rapor-

\footnotetext{
${ }^{9}$ Союз журналистов России примет новый вариант Кодекса этики журналиста, http://ria. ru/society/20131023/972125394.html (dostęp: 12.09.2016).

${ }^{10} \mathrm{http}: / / \mathrm{rkn} . g o v . r u /$ (dostęp: 15.09.2016).
} 
cie. Obszarami szczególnego zainteresowania badaczy były między innymi: struktura zawodu dziennikarskiego oraz wartości i ideały zawodowe. Podstawowe pytanie towarzyszące badaniom brzmiało: czy istnieje zbieżność pomiędzy kulturami dziennikarskimi w różnych krajach oraz jak wymienione wyżej czynniki wpływają na ten proces?

Wyniki badań przeprowadzonych wśród rosyjskich dziennikarzy, o których pisze Maria Anikina, socjolog mediów z Uniwersytetu im. Łomonosowa z Moskwy, pokazały, że aż 31\% dziennikarzy rosyjskich (najwięcej z badanych krajów) stwierdziło, że do ich funkcji należy przekazywanie pozytywnego obrazu kraju, 72\% wskazało na dostarczanie interesujących informacji, 71\% na dostarczanie informacji politycznych, i tylko 46\%, tj. najmniej ze wszystkich 12 krajów - na motywowanie ludzi.

Wstępny raport na temat pracy dziennikarza w Polsce przygotowała Bogusława Dobek-Ostrowska z Uniwersytetu Wrocławskiego. Autorka omawia badania przeprowadzone w Polsce przez kilku naukowców po 1989 r. Z jej badań wynika, że 62,6\% badanych dziennikarzy obawiało się, że media mogą być użyte jako narzędzie rządowej lub prezydenckiej propagandy, 58,4\%, że wykorzystane mogą być dla politycznej mobilizacji społeczeństwa, a jednocześnie $40 \%$ respondentów nie oponowało przeciw politycznemu zaangażowaniu dziennikarzy. $\mathrm{Z}$ badań wynika także, że $65 \%$ wskazywało na istnienie pełnej wolności lub wolności w swojej pracy, 21,6\% było bardzo zadowolonych, a 70\% zadowolonych ze swojej pracy.

Warto nadmienić, że w raporcie używane jest sformułowanie „kultura dziennikarska", którą prof. Thomas Hanitzsch, naukowiec z Uniwersytetu Monachijskiego w Niemczech, rozpatruje na czterech poziomach ${ }^{11}$ :

1) na poziomie poznawczym (cognitive level) - sposób, w jaki dziennikarstwo opisuje świat i selekcjonuje newsy;

2) na poziomie dziennikarskich ideałów (journalistic ideals) - przekonania i wartości dotyczące roli dziennikarzy, ich stosunek do władzy zewnętrznej i właścicieli mediów;

3) na poziomie dziennikarskiej praktyki (journalistic practices) - codzienna praca dziennikarzy, niezależność w podejmowaniu decyzji;

4) na poziomie usytuowania dziennikarzy w społeczeństwie (position of journalists in society) - prestiż zawodu, pozycja w hierarchii społecznej.

Warto przenieść ten podział na interesującą nas kulturę zawodu dziennikarza w Polsce i w Rosji.

Na poziomie poznawczym, czyli tego, w jaki sposób dziennikarze polscy i rosyjscy opisują świat i selekcjonują newsy, można dostrzec kilka wspólnych tendencji, jakie charakteryzują polskie i rosyjskie media, a które pokazują jak deklarowane w kodeksach i kartach etycznych wartości realizowane są w praktyce dziennikarskiej.

${ }^{11}$ Journalism in Russia, Poland and Sweden - traditions, cultures and research, eds. M. Anikina, B. Dobek-Ostrowska, J. Hok, G. Nygren, Stockholm 2012. 
Przekazy medialne nadmiernie przesycone są polityką. Zarówno w polskich, jak i rosyjskich mediach widać wyraźną manipulację informacjami. Media sztucznie kreują tematy debaty publicznej, skupiając uwagę opinii publicznej na jednym lub kilku sprawach, odwracając uwagę od kwestii bardziej istotnych. Nadawcy telewizyjni najczęściej manipulują na poziomie emocjonalnym. W kulturze medialnej obu krajów dominującą ideą postmodernistyczną jest konsumpcjonizm, wartości hedonistyczne i witalne, jak również nasycenie informacjami społecznie negatywnymi, w związku z czym przeważają pesymistyczne wiadomości.

$\mathrm{Na}$ kolejnym poziomie kultury - dziennikarskich ideałów (journalistic ideals) - dostrzegalne są różnice w polskiej i rosyjskiej kulturze dziennikarskiej, na którą składają się przekonania i wartości dotyczące roli dziennikarzy, ich stosunek do władzy zewnętrznej i właścicieli mediów. Mówiąc o etycznym zachowaniu dziennikarzy i reprezentowanych przez nich wartościach, nie można nie uwzględnić działań konkretnych ludzi - zwłaszcza redaktorów prowadzących i naczelnych, którzy promują subiektywny przekaz informacyjny, mijając się tym samym z najważniejszą wartością dziennikarską, jaką jest prawda.

W rosyjskim środowisku dziennikarskim miejsce zatrudnienia w znaczący sposób determinuje dziennikarskie wartości i stosunek do władzy. Warto podkreślić, że praca $\mathrm{w}$ agencjach prasowych, dziennikach lub stacjach telewizyjnych dotowanych z budżetu federalnego jednoznacznie określa rolę dziennikarza jako służbisty. Przykładem takiego bezkrytycznego stosunku do władzy, a głównie prezydenta Putina jest szefowa anglojęzycznej stacji Russia Today, Margarita Simonian, która uważa, że w dziennikarstwie najważniejszą wartością jest osobisty pogląd dziennikarza:

Prowadzący program, który ma swoje poglądy, powinien traktować ostro tych, z którymi się nie zgadza. Róbmy to, czego chcą odbiorcy, a nie to, czego nas uczyli w podręcznikach dziennikarstwa 10 lat temu ${ }^{12}$.

W innej swojej wypowiedzi redaktorka podkreśla, że dziennikarstwo nie pełni takich samych funkcji jak kiedyś, czyli informacyjnych i służebnych wobec społeczeństwa, obecnie bowiem większe znaczenie mają oglądalność i wyniki finansowe.

Dziś to widzowie decydują o ofercie programowej telewizji:

Dziennikarstwo czasem jest biznesem, czasem służeniem prawdzie, ale nigdy nie jest bezmyślną grafomanią. To zależy od dziennikarza i od medium, w którym pracuje, ale w pierwszej kolejności od wymagań audytorium ${ }^{13}$.

${ }^{12}$ http://www.press.pl/opinie/pokaz/2183,Koniec-obiektywizmu-\%E2\%80\%93-robmy_-co-chcawidzowie (dostęp: 12.09.2016) (tłum. aut.).

${ }_{13}^{3}$ Маргарита Симоньян: Мы с Тиной не будем беспристрастными, http://www.kp.ru/daily/ 26033/2949758/ (dostęp: 12.09.2016) (tłum. aut.). 
Zadaniem dziennikarzy pracujących dla Russia Today jest wykreowanie spójnego obrazu rzeczywistości, który zdaniem władz rosyjskich zniekształcany jest przez wielu zewnętrznych wrogów.

Drugą osobą, która realizuje polityczne zamówienia i przenosi je na grunt dziennikarski, jest redaktor Dmitrij Kisielow, dziennikarz prowadzący niezwykle popularny w Rosji program „Wiesti niedieli”, a także zastępca dyrektora Wszechrosyjskiej Państwowej Kompanii Telewizyjno-Radiowej. Kisielow słynie z radykalnie prokremlowskich i konserwatywnych poglądów, które prawdopodobnie wpłynęły na to, że został nowym generalnym dyrektorem agencji „Rossija Siegodnia”, która ma informacyjnie i propagandowo wspierać wewnętrzną i zewnętrzną politykę Federacji Rosyjskiej. Nowy dyrektor zwrócił się z kategorycznym stwierdzeniem do dziennikarzy, którzy pracują w agencji, uświadamiając im, jakie wartości są dla nich najważniejsze:

[...] Jeśli zamierzacie uprawiać sabotaż, to nie odpowiada to moim planom. Praca w agencji musi się wiązać z miłością do Rosji ${ }^{14}$.

Do grona znanych i cenionych dziennikarzy stacji NTW należy również Leonid Parfionow (rocznik 1960) ${ }^{15}$, który jednak inaczej postrzega relacje dziennikarzy i władzy, a także wartości, które są ważne w tym zawodzie. Parfionow karierę rozpoczynał od pracy w znanych radzieckich gazetach, takich jak „Правда”, „Огонек”, „Московские новости". Dziennikarz zdecydowanie lepiej realizował się na gruncie dziennikarstwa telewizyjnego, ale największą popularność zdobył jako prowadzący program „Намедни”, emitowany od 1990 r. w TV Centr, a następnie, od 1993 do 2004 r., na kanale NTW. W końcu stycznia 2003 r. Parfionow został nagrodzony cenioną w środowisku dziennikarskim nagrodą telewizyjną TEFI w kategorii „Program analityczno-informacyjny" ${ }^{\prime \prime}$. Otrzymał również nagrodę rosyjskiej prasy za najlepszą książkę opartą na swoim programie „Намедни” w 2009 r. napisaną przez dziennikarza. Parfionow zwrócił uwagę rosyjskiego środowiska dziennikarskiego w dniu, w którym przyznano mu nagrodę Władysława Listiewa za wysoki poziom i profesjonalizm dziennikarski (październik 2010 r.). Jego wystąpienie było dla wielu osób szokujące, ponieważ redaktor odważył się publicznie nawiązać do najbardziej drażliwych problemów trawiących rosyjskie środowisko dziennikarskie, tj. ataków fizycznych, gróźb, a nawet zabójstw. Redaktor za najgorsze uznał uwikłanie dziennikarzy w układy polityczne, co nie pozwala na rzetelne przygotowanie określonych tematów.

[...] Za każdą mającą polityczne znaczenie audycją stoją cele i zadania władz, jej nastrój, opinie, jej przyjaciele i wrogowie. Formalnie to w ogóle nie są informacje, a PR władzy albo anty-PR - czego jaskrawym przykładem było przygotowanie w telewizji gruntu pod

${ }^{14}$ Dmitrij Kisielow, czyli patriotyzm urabiany medialnie, http://www.wiadomosci24.pl/artykul/dmitrij_kisielow_czyli_patriotyzm_urabiany_medialnie_300287.html (dostęp: 30.10.2014).

${ }^{15} \mathrm{http} / / /$ ruj.ru/docs/itogi-2000.html, 30.10 .2014 (dostęp: 12.09.2016) (tłum. aut.).

${ }^{16} \mathrm{http}: / /$ leonidparfenov.ru/biografiya/ (dostęp: 12.09.2016). 
dymisję Łużkowa. I, oczywiście, auto-PR władzy. Dla korespondenta państwowego kanału telewizyjnego osoby na wyższych stanowiskach to nie potencjalni bohaterowie newsów, ale kierownicy jego kierownika. Formalnie korespondent nie jest wtedy w ogóle dziennikarzem, a urzędnikiem, postępującym zgodnie z logiką służenia i podwładności. Z kierownikiem kierownika nie można, na przykład, przeprowadzić wywiadu w prawdziwym znaczeniu tego słowa - czyli próby otworzenia kogoś, kto nie chciał by się otwierać17.

A jak wygląda realizacja dziennikarskich zasad w polskich redakcjach? Czy polscy dziennikarze w praktyce zawodowej dążą do zobiektywizowania przekazu? Wydaje się, że trudno znaleźć tytuł prasowy lub stację telewizyjną, w której nie pojawią się dziennikarze z własnym systemem wartości, doświadczeniami i stereotypowym myśleniem. Istnieją przecież instytucjonalne redagowania i prezentowania tekstów. Ryszard Kapuściński, wybitny polski reporter, wybrany dziennikarzem XX w. w Polsce, w jednej ze swoich wypowiedzi negatywnie ocenił sposób realizacji zasady obiektywizmu w dziennikarstwie:

Nie wierzę w bezstronne dziennikarstwo, nie wierzę w formalny obiektywizm. Dziennikarz nie może być obojętnym świadkiem, powinien posiadać zdolność, którą w psychologii nazywa się empatią.. Tak zwane dziennikarstwo obiektywne jest niemożliwe w sytuacjach konfliktów. Próby obiektywizmu w takich sytuacjach prowadzą do dezinformacji ${ }^{18}$.

Andrzej Skworz, redaktor naczelny magazynu dla dziennikarzy „Press”, również zauważa obecnie wśród polskich dziennikarzy modę na nieobiektywizm i afiszowanie się ze swoimi poglądami politycznymi, co oddala polskie dziennikarstwo od standardów anglosaskich.

Wydawcy jeszcze 10 lat temu chętnie rozmawiali o kodeksach etycznych, dziś tego tematu nikt nie dotyka. Wszyscy wiedzą, że robimy w konia odbiorców. Oni się na to godza, kupują nas z dobrodziejstwem inwentarza, bo jeszcze jakieś wartości w tradycyjnych mediach widzą, choć z każdym rokiem mniej. Tymczasem edukacji medialnej powinno się uczyć już w podstawówkach; tłumaczyć dzieciom, na czym polega krytyczny odbiór mediów, rozpoznawanie, co może być przekrętem z powodów finansowych, reklamowych czy politycznych ${ }^{19}$.

Na poziomie praktyki dziennikarskiej (journalistic practices) i postrzegania zawodu dziennikarskiego w społeczeństwie można dostrzec różnice zarówno w pracy dziennikarzy, jak i stopnia niezależności w podejmowaniu przez nich decyzji.

${ }^{17}$ L. Parfionow, Trzeba chociaż nazwać rzeczy po imieniu, 1.12.2010, http://www.kresy.pl/publicy styka,reportaze?zobacz/leonid-parfionow-trzeba-chociaz-nazwac-rzeczy-po-imieniu (dostęp: 12.09.2016) (thum. aut.).

${ }^{18} \mathrm{M}$. Twaróg, Czy istnieje obiektywizm dziennikarski?, http://www.dziennikzachodni.pl/artykul/ 226334,czy-istnieje-obiektywizm-dziennikarski,id,t.html (dostęp: 14.09.2016).

${ }^{19}$ A. Skworz, Wszyscy wiedza, że media robiq w konia odbiorców [wywiad B. Sowa, M. Birecka], 14.10.2015, http://wiadomosci.dziennik.pl/media/artykuly/502919, andrzej-skworz-naczelny-presso-mediach-po-wyborach-obiektywizmie-i-podzialach-wsrod-dziennikarzy.html (dostęp: 12.09.2016). 
Silna ingerencja państwa $\mathrm{w}$ rosyjskie kanały telewizyjne jest podkreślana przez samych dziennikarzy tych instytucji. Kiedy 26 kwietnia 2012 r. prezydent Dmitrij Miedwiediew spotkał się z dziennikarzami pięciu kanałów telewizyjnych, w tym NTW, REN-TV, WGTRK, Pierwszego Kanału i telewizji internetowej Dożd, jeden z dziennikarzy stacji państwowej NTW poinformował prezydenta, że jako dziennikarz państwowej stacji regularnie napotyka ograniczenia niepozwalające mu wypełniać obowiązki dziennikarza. Miedwiediew odpowiedział, że każde medium przyjmuje jakieś polityczne stanowisko, a z drugiej strony przypomniał dziennikarzom, że cenzura w konstytucji rosyjskiej jest zabroniona, dlatego jakiekolwiek próby cenzurowania to powód do ingerencji państwa. Kierownictwu mass mediów zalecił odpowiedzialność i poszukiwanie „wewnętrznej chemii” pomiędzy kierownictwem, dziennikarskim kolektywem i potrzebami audytorium, które powinny się nawzajem harmonizować ${ }^{20}$. Taka wizja relacji wewnątrzredakcyjnych z pewnością zaskoczyła wielu dziennikarzy, tym bardziej że wypowiedział je prawnik cywilista, który powinien posługiwać się specjalistycznym słownictwem opartym na konkretnych przepisach prawa prasowego, a nie pojęciami na granicy chemii i harmonii.

Ostatni poziom kultury dziennikarskiej to usytuowanie dziennikarzy w społeczeństwie i w opinii międzynarodowej (position of journalists in society) - warto prześledzić, jak kształtuje się zaufanie społeczne do mediów polskich i rosyjskich odbiorców.

Aleksander Koroczenskij w artykule Krytyka mediów w Rosji. Stan aktualny, rola spoleczna, perspektywy, opublikowanym w polskich „Zeszytach Prasoznawczych", stwierdzil, że wśród społeczeństwa rosyjskiego znacząco wzrosła nieufność do mediów - w porównaniu z początkiem lat dziewięćdziesiątych - wówczas dziennikarzom ufało 70\% społeczeństwa, a po 10 latach zaufanie to spadło do 30\% w 2004 r., a w 2013 r. tylko do 17\%! (red. $)^{21}$. Koroczenskij wyjaśnia tę sytuację następująco:

Rosyjskie media działają dziś na patologicznym rynku informacyjnym, charakteryzują się nierównością warunków konkurencji, silną zależnością instytucji medialnych od państwowych dotacji. A społeczeństwo rosyjskie nie ma dziś realnej możliwości skutecznego wpływania na państwowe i komercyjne media ${ }^{22}$.

Wspomniany wcześniej dziennikarz i redaktor Leonid Parfionow podkreślił w swoim słynnym przemówieniu, że stosunek społeczeństwa rosyjskiego do dziennikarzy niepokoi i jest wyrazem niezrozumienia tego zawodu.

${ }^{20}$ Медведев: иеенура в СМИ является поводом для вмешательства государства, 26.04.2012, http://ria.ru/politics/20120426/635779696.html (dostęp: 12.09.2016).

${ }^{21}$ European Trusted Brands to jedno z największych i najszerzej zakrojonych badań konsumenckich w Europie. Jego organizatorem jest magazyn „Reader's Digest”.

${ }^{22}$ A. Koroczenskij, Krytyka mediów w Rosji, „Zeszyty Prasoznawcze”, Kraków 2005, s. 92. 
Jeszcze straszniejsze jest to, że większa część społeczeństwa już nie potrzebuje dziennikarstwa. Kiedy dziwią się: no pobili, i co z tego! Mało to kogo u nas biją? Dlaczego z powodu jakiegoś reportera tyle zamieszania? Miliony ludzi nie rozumieją że dziennikarz, idąc na zawodowe ryzyko, robi to dla swojego audytorium. Dziennikarza biją nie za to, że napisał, powiedział czy sfilmował. Ale za to, że to przeczytali, usłyszeli albo zobaczyli ${ }^{23}$.

Czy niskie notowania Rosji w zagranicznych rankingach odstraszają i demotywują młodych ludzi do pracy dziennikarskiej? Dziennikarz „Izwiestii”, Andriej Kolesnikow wyjaśnia, że nowe kadry elastycznie dopasowują się do istniejących uwarunkowań polityczno-prawnych, ucząc się warsztatu i przyjmując zachowawczą postawę:

Praca młodych dziennikarzy - zwłaszcza na prowincji - coraz częściej polega na umiejętności adaptowania się do stylu i zależności politycznych redakcji. [...] Autocenzura niszczy nasze redakcje, zabija zasadę niezależności. Wszyscy doskonale rozumieją, o co chodzi w tej grze, prywatnie mówią o tym dość otwarcie, ale jeśli chcesz pracować, to musisz zaakceptować reguły gry ${ }^{24}$.

A zatem w Rosji mass mediom ufa mniej niż jedna trzecia ludności, podczas gdy na początku lat dziewięćdziesiątych ten poziom przewyższał $70 \%{ }^{25}$. Według badań przeprowadzonych przez European Trusted Brands, rankingu miesięcznika „Reader's Digest" w Polsce poziom zaufania społecznego w 2013 r. do dziennikarzy sięgał 33\% ${ }^{26}$.

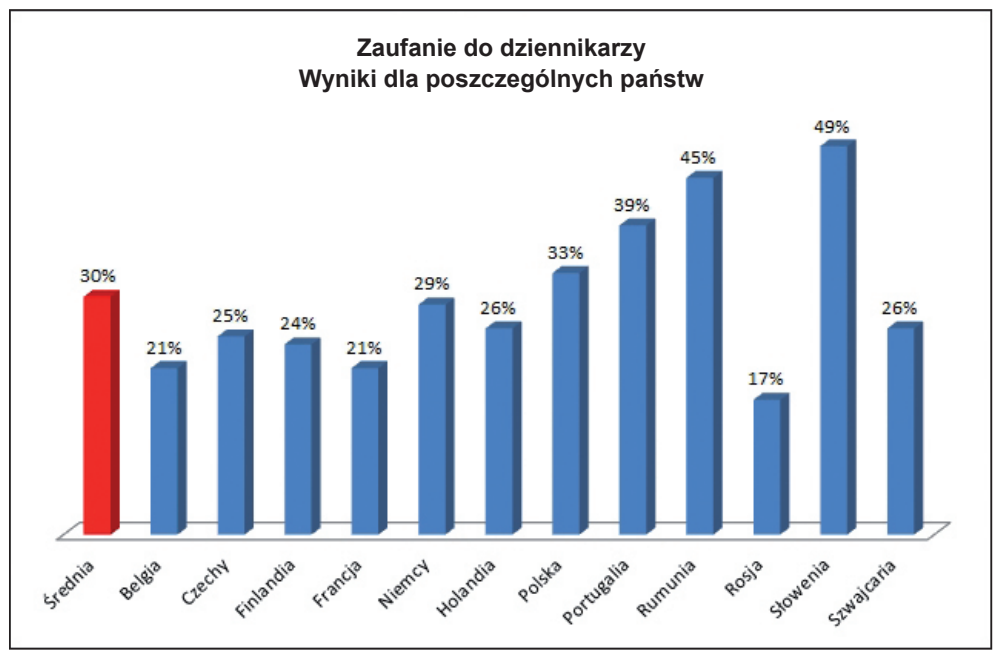

${ }^{23} \mathrm{http}: / /$ www.kresy.pl/publicystyka,reportaze?zobacz/leonid-parfionow-trzeba-chociaz-nazwacrzeczy-po-imieniu (dostęp: 15.09.2016).

${ }^{24}$ Wywiad A. Kolesnikowa z M. Wojciechowskim, Rosyjskie media niszczq cynizm i autocenzura, 10.10.2006, http://wyborcza.pl/1,75248,3676638.html (dostęp: 15.09.2016).

${ }^{25}$ A. Koroczenskij, Krytyka mediów..., s. 91.

${ }^{26}$ „Reader's Digest” z 12 czerwca 2013 r. 


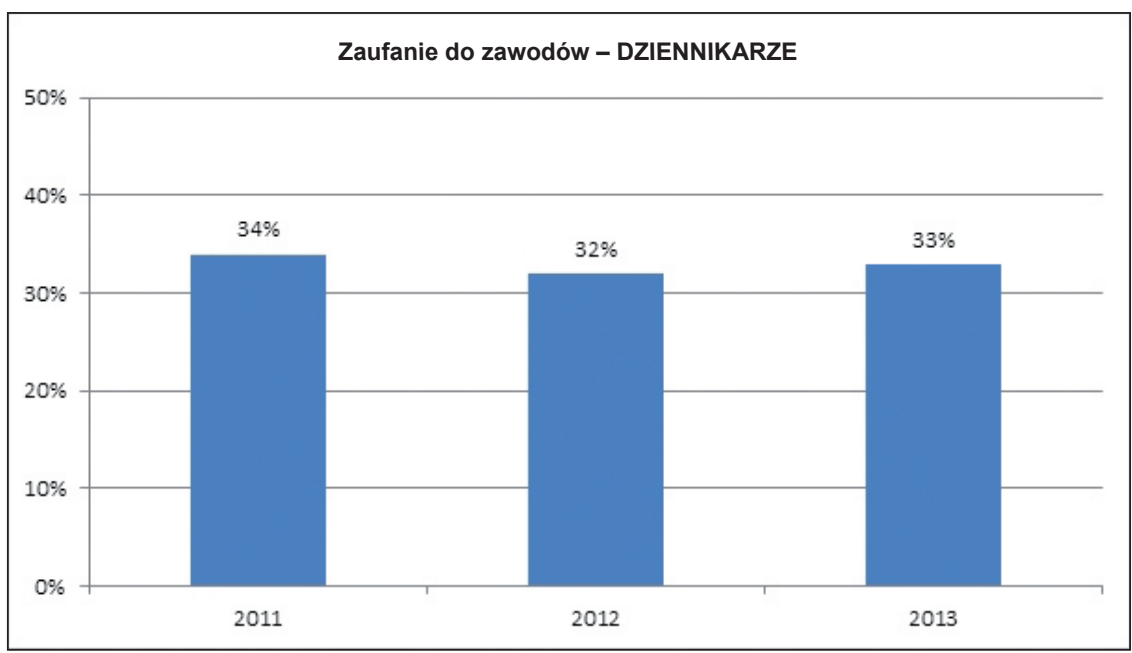

Zaufanie do dziennikarzy w Polsce, źródło: http://www.marketing-news.pl/photos/upd/130517111701 trusted_brands_3_large.jpg.

W opinii międzynarodowych organizacji dziennikarskich, które badają wskaźnik zaufania społecznego i niezależności mediów, Polska i Rosja lokują się w zupełnie odmiennych poziomach wolności słowa.

Co roku międzynarodowe organizacje dziennikarskie przygotowują raporty na temat wolności słowa, uwzględniając nie tylko kontekst prawny obowiązujący w danym kraju, lecz także stopień monopolizacji, cenzury, ataków słownych lub fizycznych. Warto wspomnieć o trzech takich instytucjach, które analizują pracę dziennikarzy między innymi w Polsce i Rosji. Organizacja „Reporterzy bez Granic” z siedzibą w Paryżu publikuje co roku listę rankingową, opartą na ankietach rozsyłanych do 180 krajów na świecie, w której zawarte są 42 pytania określające swobodę warunków pracy i publikacji dla dziennikarzy ${ }^{27}$. Inną organizacją przygotowującą coroczny raport jest Freedom House, amerykańska organizacja typu non profit działająca od $1980 \mathrm{r}$. W raporcie uwzględnia 197 krajów, które oznaczone są później na mapie świata jako „wolne”, „częściowo wolne” lub „niewolne”28. Z kolei dogłębne analizy poziomu niezależności mediów w ponad 80 krajach na świecie przeprowadza IREX - amerykańska organizacja działająca od 1968 r., organizująca także szkolenia i seminaria dla redaktorów i dziennikarzy ${ }^{29}$. Poniższe tabele pokazują miejsce Polski i Rosji w raportach ostatnich lat $(2013,2014,2015)$.

${ }^{27}$ http://en.rsf.org/ (dostęp: 12.09.2016).

${ }^{28} \mathrm{http} / / / \mathrm{www}$.freedomhouse.org/report-types/freedom-press\#.UxNCH7mYbIU (dostęp: 12.09. 2016).

${ }^{29} \mathrm{http}: / / w w w . i r e x . o r g /$ regions (dostęp: 15.09.2016). 


\section{Pozycja Rosji w indeksach wolności prasy}

\begin{tabular}{|c|c|c|c|}
\hline 2013 & Reportes without borders & Freedom House & IREX \\
\hline 2014 & 148. pozycja na 180 państw $^{30}$ & $\begin{array}{c}5,5(1=\text { najlepsze, } 7= \\
\text { najgorsze })^{31}\end{array}$ & $\begin{array}{c}\text { Ogólna liczba } \\
\text { punktów }-1,52^{32}\end{array}$ \\
\hline 2015 & 148. na 180 państw $^{33}$ & $\begin{array}{c}5,5(1=\text { najlepsze, } 7= \\
\text { najgorsze }^{34}\end{array}$ & $\begin{array}{c}\text { Ogólna liczba } \\
\text { punktów }-1,52^{35}\end{array}$ \\
\hline 152. na 180 państw $^{36}$ & $\begin{array}{c}6,0(1=\text { najlepsze, } 7= \\
\text { najgorsze }^{37}\end{array}$ & $\begin{array}{c}\text { Ogólna liczba } \\
\text { punktów }-1,27^{38}\end{array}$ \\
\hline
\end{tabular}

\section{Pozycja Polski w indeksach wolności prasy}

\begin{tabular}{|c|c|c|c|}
\hline & Reportes without borders & Freedom House & IREX $^{39}$ \\
\hline 2013 & 22. na 180 państw ${ }^{40}$ & $\begin{array}{c}1,0(1=\text { najlepsze }, 7= \\
\text { najgorsze })^{41}\end{array}$ & - \\
\hline 2014 & 19. na 180 państw ${ }^{42}$ & $\begin{array}{c}1,0(1=\text { najlepsze, } 7= \\
\text { najgorsze })^{43}\end{array}$ & - \\
\hline 2015 & 18. na 180 państw ${ }^{44}$ & $\begin{array}{c}1,0(1=\text { najlepsze }, 7= \\
\text { najgorsze }^{45}\end{array}$ & - \\
\hline
\end{tabular}

Źródło: opracowanie własne oparte na listach rankingowych wymienionych wyżej organizacji.

\section{Uwagi dotyczące rankingów wolności prasy}

Wymienione rankingi wolności prasy przynoszą wątpliwości dotyczące nie tylko stosowanej metodologii, lecz także samych organizacji, które inaczej definiują wolność prasy niż Rosjanie. Te różnice kulturowe stały się również przyczynkiem do publika-

${ }^{30} \mathrm{http} / / /$ en.rsf.org/press-freedom-index-2013,1054.html (dostęp: 15.09.2016).

${ }^{31} \mathrm{http}: / / \mathrm{www}$.freedomhouse.org/report/freedom-world/2013/russia\#.UxOL1 bmYbIU (dostęp: 12.09.2016).

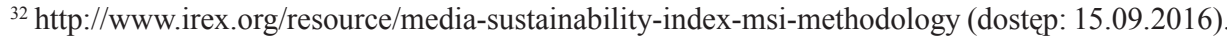
Niska punktacja oznacza niestabilny system medialny, kraj zapewnia minimum podstaw prawnych.

${ }^{33}$ https://index.rsf.org/\#!/ (dostęp: 15.09.2016).

${ }^{34} \mathrm{https}$ ://freedomhouse.org/report/freedom-world/2014/russia (dostęp: 12.09.2016).

${ }^{35} \mathrm{https} / / /$ www.irex.org/sites/default/files/u105/EE_MSI_2014_Russia.pdf(dostęp: 12.09.2016).

${ }^{36}$ https://index.rsf.org/\#!/ (dostęp: 15.09.2016).

${ }^{37} \mathrm{https}$ ://freedomhouse.org/report/freedom-world/2015/russia (dostęp: 15.09.2016).

${ }^{38} \mathrm{https} / /$ www.irex.org/sites/default/files/u105/EE_MSI_2015_Russia.pdf (dostęp: 15.09.2016).

${ }^{39}$ Dotyczy krajów rozwijających się w Europie i Eurazji.

${ }^{40}$ https://index.rsf.org/\#!/ (dostęp: 15.09.2016).

${ }^{41} \mathrm{https}$ ://freedomhouse.org/report/freedom-world/2013/poland (dostęp: 12.09.2016).

${ }^{42}$ https://index.rsf.org/\#!/ (dostęp: 15.09.2016).

${ }^{43} \mathrm{https}$ ://freedomhouse.org/report/freedom-world/2014/poland (dostęp: 15.09.2016).

${ }^{44}$ https://index.rsf.org/\#!/ (dostęp: 15.09.2016).

${ }^{45} \mathrm{https}$ ///freedomhouse.org/report/freedom-world/2015/poland (dostęp: 12.09.2016). 
cji książki, której redakcję objęły Monroe E. Price, profesor prawa na Uniwersytecie Pensylwania, Susan Abbott, zastępca programu rozwoju w organizacji medialnej Internews Network, i Libby Morgan, dyrektor Centrum Globalnych Studiów Komunikacji na Uniwersytecie Pensylwania. Lee Becker i Tudor Vlad z Uniwersytetu Georgia ocenili korelacje wynikające $\mathrm{z}$ raportów wymienionych organizacji: Reporterzy bez Granic, Freedom House oraz IREX i uznali je za wysoce wiarygodne ${ }^{46}$. Naukowcy podkreślili jednak, że wskaźniki poziomu wolności opierają się na zachodnim, amerykańskim rozumieniu pojęcia wolności prasy. W uzasadnieniu piszą:

Freedom House oraz Reporterzy bez Granic zwracają uwagę przede wszystkim na wolność i niezależność mediów w stosunku do kontroli rządowej, w mniejszym stopniu zwracając uwagę na wpływy interesów komercyjnych i korporacyjnych ${ }^{47}$.

Z kolei naukowiec z niemieckiego Uniwersytetu Nürnberg, doktor Christina Holtz-Bacha przedstawiła w swoim artykule Wolność prasy na świecie: czy porównywanie jest możliwe i potrzebne? (tłum. aut.) wattpliwości co do definicji wolności $\mathrm{w}$ rankingach prasy, ponieważ nie została ona dokładnie sformułowana ${ }^{48}$. Naturalnie można się więc zastanawiać, na ile otrzymane w raportach wyniki są wymierne i w jakim stopniu oddają sytuację mediów w obydwu krajach.

Wydaje się, że cenione wartości zawodu dziennikarza w Polsce i w Rosji będą ewoluować, ponieważ muszą dostosowywać się do zmian społeczno-kulturowych, a stan przyszłych polskich i rosyjskich mediów zależeć będzie nie tylko od przekazywanych przez nie wartości, ale i jakości samych mass mediów.

\section{Literatura}

Becker L. B., Vlad T., The Conceptualization and Operationalization of Country-Level Measures of Media Freedom [w:] Measures of Press Freedom and Media Contributions to Development, Seria „Mass Communication and Journalism” 2011, Vol. 4, New York-Bern-Berlin-Bruxelles-Frankfurt am Main-OxfordWien.

\footnotetext{
${ }^{46} \mathrm{http}$ //pl.ejo-online.eu/2298/wolnosc-prasy-2/czy-rankingi-wolnosci-prasy-sa-wiarygodne (dostęp: 12.09.2016).

${ }^{47}$ L. B. Becker, T. Vlad, The Conceptualization and Operationalization of Country-Level Measures of Media Freedom [w:] Measures of Press Freedom and Media Contributions to Development, Seria „Mass Communication and Journalism” 2011, Vol. 4, New York-Bern-Berlin-Bruxelles-Frankfurt am Main-Oxford-Wien, s. 23.

${ }^{48}$ Freedom of the Press: Is a Worldwide Comparison Possible and What is it Good For? [w:] Measures of Press Freedom and Media Contributions to Development, Seria „Mass Communication and Journalism" 2011, Vol. 4, New York-Bern-Berlin-Bruxelles-Frankfurt am Main-Oxford-Wien, s. 129.
} 
Dmitrij Kisielow, czyli patriotyzm urabiany medialnie, http://www.wiadomosci24. pl/artykul/dmitrij_kisielow_czyli_patriotyzm_urabiany_medialnie_300287.html. Dziennikarski Kodeks Obyczajowy, http://www.krrit.gov.pl/Data/Files/_public/pliki/ publikacje/analiza2006_07.pdf, http://centruminformacji.tvp.p1/15781040/dziennikarski-kodeks-obyczajowy-stowarzyszenia-dziennikarzy-rzeczypospolitejpolskiej, www.sdp.pl/kodeks.

Freedom of the Press: Is a Worldwide Comparison Possible and What is it Good For?

[w:] Measures of Press Freedom and Media Contributions to Development, Seria „Mass Communication and Journalism” 2011, Vol. 4, New York-Bern-Berlin-Bruxelles-Frankfurt am Main-Oxford-Wien. http://en.rsf.org/.

http://en.rsf.org/press-freedom-index-2013,1054.html.

http://leonidparfenov.ru/biografiya/.

http://pl.ejo-online.eu/2298/wolnosc-prasy-2/czy-rankingi-wolnosci-prasy-sa-wiarygodne.

Союз журналистов России примет новый вариант Кодекса этики журналиста, http://ria.ru/society/20131023/972125394.html.

http://rkn.gov.ru/.

http://ruj.ru/docs/itogi-2000.html.

http://www.freedomhouse.org/report/freedom-world/2013/russia\#.UxOL1bmYbIU. http://www.freedomhouse.org/report-types/freedom-press\#.UxNCH7mYbIU. $\mathrm{http}: / / \mathrm{www}$.irex.org/regions.

http://www.irex.org/resource/media-sustainability-index-msi-methodology. http://www.kp.ru/daily/26033/2949758/.

http://www.marketing-news.pl/photos/upd/130517111701_trusted_brands_3_large.jpg. http://www.press.pl/opinie/pokaz/2183,Koniec-obiektywizmu-\%E2\%80\%93-rob-

my_-co-chca-widzowie.

https://freedomhouse.org/report/freedom-world/2013/poland. https://freedomhouse.org/report/freedom-world/2014/poland. https://freedomhouse.org/report/freedom-world/2015/poland. https://freedomhouse.org/report/freedom-world/2015/russia. https://www.irex.org/sites/default/files/u105/EE_MSI_2014_Russia.pdf. https://www.irex.org/sites/default/files/u105/EE_MSI_2015_Russia.pdf. Jazownik L., Społeczny sens oraz społeczne funkcjonowanie wartości, aksjologii i edukacji aksjologicznej. Analiza metadyskursywna i jej edukacyjne implikacje [w:] Czytanie tekstów kultury. Metodologia-badania-metodyka, red. B. Myrdzik, I. Morawska, Lublin 2007. Journalism in Russia, Poland and Sweden - traditions, cultures and research, eds. M. Anikina, B. Dobek-Ostrowska, J. Hok, G. Nygren, Stockholm 2012. 
Koroczenskij A., Krytyka mediów w Rosji, „Zeszyty Prasoznawcze”, Kraków 2005. Parfionow L., Trzeba chociaż nazwać rzeczy po imieniu, http://www.kresy.pl/publicy styka,reportaze?zobacz/leonid-parfionow-trzeba-chociaz-nazwac-rzeczy-poimieniu.

Puzynina J., Wartości, etyka, sacrum w języku [w:] Polonistyka w przebudowie, t. 2, red. M. Czermińska i in., Kraków 2005.

Skworz A., Wszyscy wiedza, że media robia w konia odbiorców [wywiad B. Sowa, M. Birecka], 14.10.2015, http://wiadomosci.dziennik.pl/media/artykuly/ 502919, andrzej-skworz-naczelny-press-o-mediach-po-wyborach-obiektywizmiei-podzialach-wsrod-dziennikarzy.html.

Twaróg M., Czy istnieje obiektywizm dziennikarski?, http://www.dziennikzachodni. $\mathrm{pl} /$ artykul/226334,czy-istnieje-obiektywizm-dziennikarski,id,t.html.

Ustawa z 26 stycznia 1984 r. - Prawo prasowe, Dz. U. nr 5, poz. 24 ze zm.

Wywiad A. Kolesnikowa z M. Wojciechowskim, Rosyjskie media niszcza cynizm i autocenzura, 10.10.2006, http://wyborcza.pl/1,75248,3676638.html.

Медведев: иензура в СМИ является поводом для вмешательства государства, 26.04.2012, http://ria.ru/politics/20120426/635779696.html. 